\title{
Announcement and call for papers
}

\section{FID Congress 1984}

The 42nd FID Congress will convene in The Hague on 24 through 27 September 1984, and is being organized by the Dutch National Member of FID, the Nederlands Orgaan voor de Bevordering van de Informatieverzorging (NOBIN). The Congress, with the theme "The Use of Information in a Changing World", will be made up of seven plenary sessions, and papers are invited to be submitted for presentation in any of the sessions listed below except for Session A - "Inaugural".

The ideas proposed for the Congress programme are in many respects still of a preliminary nature.

As to the organization of the Congress itself, the aim of the Congress Organizing Committee is that the professional papers will be published and distributed before the Congress, thereby avoiding that papers be read out during the sessions. It is hoped that speakers will be able to summarize their papers in about 10 minutes time, giving short explanations and some provocative statements which will encourage discussion in a following thirty minute period.

Particular attention is being focused on the user and the non-user of information; the production as such of secondary information will not be described, unless certain elements of it are directly aimed at the needs and the assimilation of the potential user. The emphasis is in fact on the last link in the information transfer chain, the user.

In the framework of the changing world it is evident that the use of information for professional or occupational purposes must have a dominant place. This changing world implies the recognition of the necessity of information as a "raw material", e.g. switching the attention from the offer to the demand for information, particularly if seen against the background of economic situations.

The Congress Organizing Committee hopes that actual experiences will be presented by authors on ways in which tailor made transfer to the end-user is promoted.

The theme of the 1984 Congress is a logical follow-up at this time-considering that fourteen years ago the FID Congress was held under the theme "Users of Information".

The international Congress Organizing Committee, in conjunction with the 
national Dutch Congress Committee, has drawn up the following preliminary programme.

All interested persons are invited to submit abstracts of papers which they think might be suitable for the Congress programme.

\section{Preliminary programme}

Session A - Inaugural

1. Welcome addresses

2. Keynote addresses

Session B - Use and non-use of information in general

1. Use of information for decision making

2. Stimulating the use

3. Studying the non-user

Session C - Use of information in science and research

1. For universities and academies of sciences (reports from various countries)

2. In social sciences

3. In economic sciences

4. For research in industry

5. Use of numerical/factual data

6. For innovation

Session D - Use of information in agriculture (area reports)

Session E - Use of information for industry

1. Experiences in various countries

2. For decision making

3. Small and medium-size industries (country reports)

Session F - Use of information in administration and politics (e.g. Parliaments, etc.)

Session $\mathrm{G}$ - Confrontation of the user with new developments in information

1. User-friendliness of hardware and software

2. Electronic publishing

3. Grey (non-conventional) literature

4. Marketing of information services and the cost/benefit approach

5. Use of business archives by the end-user

6. Standardization for the ultimate user

7. Machine translation

Abstracts of papers and all queries about the 1984 FID Congress should be addressed to the attention of Mr. A. van der Laan, c/o FID Secretariat, P.O. Box 90402, 2509 LK The Hague, The Netherlands. 